OPEN ACCESS

UWS Academic Portal

\title{
Managing knowledge through social media
}

Crammond, Robert; Omeihe, Kingsley; Murray, Alan; Ledger, Kirstin

Published in:

Baltic Journal of Management

DOI:

10.1108/BJM-05-2017-0133

Published: 02/07/2018

Document Version

Peer reviewed version

Link to publication on the UWS Academic Portal

Citation for published version (APA):

Crammond, R., Omeihe, K., Murray, A., \& Ledger, K. (2018). Managing knowledge through social media: modelling an entrepreneurial approach for Scottish SMEs and beyond. Baltic Journal of Management, 13(3), 303-328. https://doi.org/10.1108/BJM-05-2017-0133

\section{General rights}

Copyright and moral rights for the publications made accessible in the UWS Academic Portal are retained by the authors and/or other copyright owners and it is a condition of accessing publications that users recognise and abide by the legal requirements associated with these rights.

Take down policy

If you believe that this document breaches copyright please contact pure@uws.ac.uk providing details, and we will remove access to the work immediately and investigate your claim. 


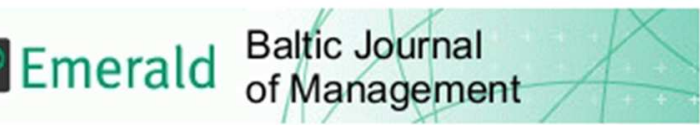

Managing Knowledge through Social Media: Modelling an Entrepreneurial Approach for Scottish SMEs and Beyond

\begin{tabular}{|r|l|}
\hline Journal: & Baltic Journal of Management \\
\hline Manuscript ID & BJM-05-2017-0133.R3 \\
\hline Manuscript Type: & Original Article \\
\hline Keywords: & $\begin{array}{l}\text { Knowledge management, Social media, ICT, SME, Entrepreneurship, } \\
\text { Innovation }\end{array}$ \\
\hline \multicolumn{2}{|l}{} \\
\hline
\end{tabular}

SCHOLARONE ${ }^{\mathrm{m}}$

Manuscripts 


\title{
Managing Knowledge through Social Media:
} Modelling an Entrepreneurial Approach for Scottish SMEs and Beyond

\begin{abstract}

\section{Purpose}

This paper conceptualises Social Media Use (SMU) as a contributory, Knowledge Management (KM) tool towards entrepreneurial behaviour amongst Small and Medium-Sized Enterprises (SMEs). Although an underdeveloped concept in entrepreneurship, our conceptual analysis of KM presents evidence which links SMU as complementary to changing KM conventions.
\end{abstract}

\section{Approach}

Pertinent KM and SMU literature of the SME context were reviewed to form an understanding of this context. Employing a mixed method approach, a pragmatic, thematic investigation of SMU-enhanced KM was facilitated.

\section{Findings}

Substantial benefits of innovative SMU, as a management tool towards SME entrepreneurialism, were witnessed. SMU enhances the administration of real-time knowledge, encouraging creativity. However, longer-term costs of employing requisite personnel, and anticipated organisational restructuring, presents challenges. The paper identifies the potentials of social media technologies in overcoming KM issues. We propose a reasoned process model towards entrepreneurial exploitation by acknowledging systematic phases of Research, Concept, Institutionalise, Develop, Target and Assess, referred to as the RCIDTA model.

\section{Implications}

We argue that $\mathrm{KM}$, through social media, facilitates interactions to execute innovative processes within SMEs ever-changing infrastructures. It also informs nascent entrepreneurs, in considering the benefits of systematic KM, and novel SMU, opportunities. The RCIDTA model for SMEs can be utilised in improving knowledge eco-systems of entrepreneurial SMEs, promoting innovation towards sustained organisation growth.

\section{Originality}

This paper embraces the growing approach of SMEs applying SMU. SMU and its cost efficiency supports start-up activity. This paper highlights central issues concerning the exploitation of sectorspecific KM, including organisational strategy, structure, brand formation, fiscal and personnel resource allocation, and market share.

Keywords: $\quad$ KM; Social Media; ICT; Small Business; Entrepreneurship; Innovation

Paper: $\quad$ Research Paper 
Along with financial, operational, environmental, and marketable factors impacting on Knowledge Management (KM) proceeses towards Small and Medium-sized Enterprises (SMEs) prosperity (Bierly and Daly, 2007; Adner and Kapoor, 2010; Harryson et al., 2012; Kivipõld, 2015), a number of central questions are considered by owners, managers and employees: Where are we positioned now? Where do we wish to go with the idea? How will we get there? (Dalkir, 2013; Burns, 2016).

The growth and variety of Social Media Usage (SMU) has encouraged SMEs to realise their ambitions and market the product, brand, or service more readily and widely (Hanna et al., 2011; Bharati et al., 2015; Helms et al., 2017). Studies documente contemporary tools within the SME-KM context, when entering national and international markets (see Gomezelj Omerzel et al., 2011; Inkinen et al., 2015; Kivipõld, 2015; Helms et al., 2017). The application of social media reconfigures and updates small business processes, in relation to capturing, retaining, and exploiting market information (Manfreda et al., 2015; Cranefield and van Reijsen, 2017). However, how this is integrated within administrative responsibilities within these organisations are varied, fragmented, and occasionally primitive (Chua and Banerjee, 2013; Sam and Cai, 2014).

With this growing trend of businesses applying technology towards improving their competitive edge; SMEs have realised the significant implications of $\mathrm{KM}$ as a tool for driving innovation and productivity (Nonaka et al., 2000; Tranfield et al., 2006; Nunes et al., 2006; Nonaka and Von Krogh, 2009; Helms et al., 2017). The tangible advances gained from the implementation of KM become evident when large companies are able to effectively store, capture and disseminate knowledge (Soto-Acosta et al., 2010; 2014). This suggests that a shift towards the generation, representation, and transformation of knowledge could be the edge for innovative SMEs (Schulttze and Stabell, 2004; Nunes et al., 2006).

This paper addresses the issue of these varied and uncertain experiences with our uniformed, phased approach towards entrepreneurial exploitation within given markets. This model advances current social media related KM literature, towards expanding further empirical investigation within the contemporary SME context (see Gomezelj Omerzel et al., 2011). This paper also assists in providing a practical and systematic remedy towards improving organisational structure, strategy, and the maximisation of acquired and attainable resources. The growth of SMU, and ever-advancing small business innovation theory are reviewed towards ascertaining routes towards SME performance. We examine the benefits of social media when complemented with KM and its impact on entrepreneurial behaviour. Furthermore, we discuss the extent to which knowledge may be managed using social media to drive entrepreneurial strategy whilst cross fertilising ideas to promoting innovation. Within these sections, we put forward two propositions highlighting the role of KM and social media in an entrepreneurial context: what is the influence of SMU in facilitating KM innovation within SMEs?, and how can SMEs shape the implementation of social media towards new ways of productivity? Adopting a pragmatic, explanatory approach, this paper cites a wider population in the study, drawing on an analysis from selected Scottish SMEs, constructing a reflective model that will respond to business realities.

\section{Social Media Use and SMEs}

Social media is now an ever-present and widespread tool used by small businesses, allowing a given brand or service to be publicised on many electronic platforms to a worldwide audience of potential customers, associated business and diversified sectors (Hanna et al., 2011; Ngai et al., 2015; Leonardi, 2017). Twenty first century organisations regard SMU as a critical factor towards the popularity and financial success of their business (Kaplan and Haenlein, 2010; Burns, 2016).

The habitual use of SMU, encourages not only the management of knowledge but enable the organisation to evolve, with this information (Dalkir, 2013; Tsimonis and Dimitriadis, 2014; Sigala and Chalkiti, 2015). The proliferation of social media provides an influential, online environment that has spanned primary, secondary and tertiary industries, private and public organisations, for consumers of any size big or small (Sam and Cai, 2014; Soto-Acosta et al., 2010; 2014). This increased exposure bridges any potential gaps between the organisation, its management, its diverse operational workforce, and its consumers (Tidd and Bessant, 2009). 
Exploitation of SMU transcends the spheres of both internal and external stakeholders within the organisational context: the founder(s), board of directors, managers and employees, professional advisors (internal and external to the firm), investors, and on-going partners. Nevertheless, innovation across the market place, in this case the online environment, involves continuous research and development, involving the engagement of employees with stakeholders, witnessing the wider network of competitors and potential stakeholders (Sam and Cai, 2014). These aspects encompass the range of operational factors that an organisation encounters: increased competitors, managing existing products, developing new products, legislation and regulation, and economic trends.

A high priority for business owners today, such as ascertaining definitional clarifications of social media, are required to support implementation (Kaplan and Haenlein, 2010). By learning from technology and for technology for specific businesses, SMEs grow nationally and internationally (Sasi and Arenius, 2008). Industries such as information technology, and design and engineering, given their inherent reliance, need and desire on continuous research, development and innovation, discover successful entrepreneurs more than others (Nakara et al., 2012; Sigala and Chalkiti, 2015). Therefore, key acknowledgement of the advantages and disadvantages of SMU is important for organisational decision making and utilisation of predominantly scarce resources. These differing assertions of SMU have displayed various outcomes (Table 1):

\section{Table 1. Benefits and Drawbacks of SMU}

\begin{tabular}{|c|c|}
\hline Benefits & Drawbacks \\
\hline $\begin{array}{l}\text { - Fast, 'real-time' marketing and } \\
\text { - } \quad \text { Effertising activity } \\
\text { - } \quad \text { Cheap to start and maintain } \\
\text { - Increased audience share } \\
\text { - } \quad \text { Timely gauging of opinion } \\
\text { - } \quad \text { Audio / visual posting }\end{array}$ & $\begin{array}{l}\text { - Instantaneous publication of poor } \\
\text { consumer experiences } \\
\text { - Technological \& compatibility issues } \\
\text { - Ongoing administration } \\
\text { - It costs longer term: personnel \& } \\
\text { management } \\
\text { - Risk / fear of hacking (affecting } \\
\text { management data, financial information, } \\
\text { public image) }\end{array}$ \\
\hline
\end{tabular}

(Ngai et al., 2015; Sigala and Chalkiti, 2015; Helms et al., 2017)

What cannot be disputed, is that social media tools and platforms empower individuals, within the organisational context, to collaborate and understand organisational objectives, motives and operations (Vuori and Okkonen, 2012; Khodakarami and Chan, 2014; Keenan and Rowley, 2017; Leonardi, 2017).

For example, Hanna et al. (2011) assert that SM has a level of control over a brand's ecosystem. Accordingly Michaelidou et al. (2011) posit that SMU heightens the exposure of an organisations brand, vision, products, and services to a greater audience. This exposure motivates multinational organisations and SMEs to design and implement timely strategies for organisational, economic and social good, as this evolution of the internet, IT communication and SMU continues at pace (Tsimonis and Dimitriadis, 2014).

Related aspects, such as social media intelligence, can be used to link social media data towards strategic decisions and productivity. This includes examining customer attitude driving online opinions, assessing the implications of these attitudes and the ability to integrate these insights into the overall strategy (Moe and Schweidel, 2014). Sam and Chai (2014) make a case for social media as an effective platform for understanding customer needs and preferences. They support their argument by providing insights as to how Starbucks' experience of social media complements KM. In this vein, Hamoud et al. (2016) contend that KM provides a greater impact on strategic decision making with SMU. Enterprises may evaluate online information towards applying them to achieving their strategic goals. Furthermore, Ngai et al. (2015) argue that devising social media strategies and the establishment of guidelines for the implementation of an effective social media system involves 
exploiting individual behaviours and attitude for further application. Unsurprisingly, Bharati et al. (2015) explore the influences of social media on organisational knowledge and conclude that social media allows enterprises connect with their customers and suppliers towards improving the knowledge quality of the enterprise. Chua and Banerjee (2013) suggest that social media should be utilised in a reinforcing manner to provide knowledge of customers on new products while proffering ways to make their best use. Therefore, these studies strongly indicate that, although SMU represents an exciting and potentially profitable avenue that yields varied results, with its use.

Nonaka et al. (2000) previously posit that the essence of being innovative is re-creating the world through a particular vision. This view is consistent with the Japanese approach, now reflected in the mobile, technological age, where enterprises recognise that creating new KM is not just a matter of processing objective information but rather of tapping on the tacit and subjective insights of its knowledge workers (such as employees).

Harrysson et al. (2012) concur, and elevate Nonaka et al's., (2000) notion, that social media provides decisions makers with fresh strategic insights through rich real time data. As social technologies mature, enterprises become more convinced of their power as they inform competitive strategy. To achieve this, SMEs would need meet with these competitive challenges by developing the willingness to engage in social conversations.

\section{Knowledge Intensive SMEs}

Towards identifying opportunities in their markets, SMEs must use this competitive intelligence or competitive benchmarking, from SMU, to analyse the risks and opportunities in their markets using social media (Kaplan and Haenlein, 2010; Helms et al., 2017; Keegan and Rowley, 2017). This allows the enterprises to identify their weaknesses and strengths towards future decision making. The intervention of contemporary KM, through SMU, widens markets and entrepreneurial horizons to the SMEs highlighted by these figures.

Initially, established from around the 1990s, KM stemmed from the scientific discipline centred on an organisation's strategy, IT, marketing and HR activities (Dalkir, 2013). Early KM literature attempted to categorise KM activities, acknowledging the generation, accessing, embedding and transferring of knowledge from internal and external sources (Nonaka, 2000; Nonaka and Peltokorpi, 2006). A notable surge in KM literature during 2009 was witnessed, with the highest citation rates witnessed during 2012 (Akhavan et al., 2016). Institutional processes, involving prescribed KM, encourage a socialisation of knowledge building, sharing and exploitation towards meeting organisational objectives and improving the organisation as a learning and thriving entity (Nonaka and Takeuchi, 1999). In previous years, several authors identified KM practices as a systematic approach to capturing, managing and the utilisation of knowledge to ensure efficiency (Nonaka and Takeuchi, 1995; Pfeiffer and Sutton, 1999). More recently, the clear connection between SMU capturing information, towards organisationally managing such, are reflected in current strategic and opeprational management literature (see Gomezelj Omerzel et al., 2011; Vuori and Okkonen, 2012; Bharati et al., 2015; Garrido-Moreno et al., 2015).

$\mathrm{KM}$ is an elusive concept with no clear consensual definition, indeed Dalkir's (2013) attempted definition of KM incorporates both the capturing and storing of knowledge perspective with emphasis on technology and innovation. This definition highlights $\mathrm{KM}$ as a coordination of an organisation's people, technology and processes towards distinct value creation. This systematic coordination can be achieved through the use of technology to foster organisational learning and productivity. While Nickols' (2000) placed the attainment of organisational advantage at the centre of KM definitions, we agree with Dalkir's definition to provide evidence as to how KM leverages on social media to increase entrepreneurial responsiveness and innovation.

Whilst as a promotional tool for the SME, the value of SMU in the context of KM is less well understood and hard to quantify (Ngai et al., 2015). The application of social media by SMEs is often uncoordinated and ineffective and consists of the basic online broadcasting of product information (Vuori and Okkonen, 2012; Bharati et al., 2015). In terms of KM however, SMU, whilst presenting a number of organisational and economic challenges to the small business owner/manager, offers 
tremendous potential benefits via both established and emerging social media platforms (Kaplan et al., 2010).

Since the mid-2000s, SMU enables SMEs to build valuable Business to Business (B2B) and Business to Consumer (B2C) information exchanging and commercial networks, who manage valuable knowledge, to expand upon their economic, creative and entrepreneurial activities (Nakara et al., 2012). Technological innovations are central to small business and have long been regarded as a predictor of firm growth (Bailetti, 2012). It has became an evolving challenge, changing the landscape of enterprise and small business, allowing the product, service or general brand to progress through its life cycle (Nakara et al., 2012). Whilst such an application brings a range of features it is likely that only those which again clearly bring some benefit will be used by the SME. We must also understand that in the content of SMU we must consider both internal and external KM applications (Hanna et al., 2011; Scuotto et al., 2017).

Internal $K M$ within the business is critical to the effective and efficient operation of the business whilst external KM is vital in order to build a successful business (Bharati et al., 2015; Hamoud et al., 2016). SMU is particularly important towards these descriptions, and during the startup phase of the development of a business, where the entrepreneur is building and shaping their business model from information, actively seeking advice on the best way to gather the resources needed (Hanna et al., 2011).

Knowledge-intensive SMU provides an opportunity to develop effective communication channels which can converse with external networks quickly and easily with little or no cost to the business, improving organisational and market performance (Kaplan and Haenlein, 2010; Scuotto et al., 2017b). Growing businesses worry about gaining and retaining market share and the use of social media also provides the opportunity to extend and exert influence. Influence can be viewed as a commodity in itself which can be bought and sold and traded as a form of capital. Successes can be shared, learning disseminated and the sharing of ideas are encouraged leading to the stimulation of creativity and innovation. Attracting 'followers' brings credibility for the business and its products and creates 'evangelists' who then use their own networks to share information on behalf of the business and in turn create more followers.

Nevertheless, a critical lack of digital SMU skills, a lack of awareness of the value of managing knowledge, availability of time to invest in both the acquisition of digital skills and also in the generation and curation of content, create perceived barriers to the uptake of social media (Kaplan and Haenlein, 2010; Michaelidou et al., 2011).

For an organisation to be viable there must be a valuable product or service, with buyers who are willing to buy, and a location for the market to thrive (local, regional, national, international, and multinational) (Tidd and Bessant, 2009). SMU within innovative SMEs, present implied job specifications and duties, which occasionally are witnessed in marketing and developmental division, but are generally immersed throughout and along an organisation's structure. Through succinct and relevant KM processes, and utilising SMU, SMEs display and communicate its message, product or service, its image, and crucially its Unique Selling Point (USP). Theoretically, this understanding elevates Pareto's 80:20 rule of potential gain from relatively minuscule input and effort. Traditional business conventions, such as key internal (e.g. precise human resource management) and external (e.g. consumer profiling) considerations of business activity, are somewhat side-lined as SMU platforms provide a $21^{\text {st }}$ century outlet for a business's style and substance to be displayed.

Lenihan et al. (2010) state that SMEs must specialise in one aspect, focussing on a market niche, driven by detailed information that maximises their own resources and capabilities. High measured levels of assured KM and subsequent entrepreneurship translate directly into high levels of economic growth. Key attributes associated with the innovative SME profile, such as creative thinking, alertness, business planning, leadership, product development, and market engagement are encouraged, witnessed and entrenched within organisational hierarchies (Burns, 2014).

The examples discussed here posit that entrepreneurship is a catalyst for business development, innovation and growth. SMEs contribute greatly to the economy of nations and can enable communities and countries within the union to develop. Research has shown conclusively that, although many factors can prohibit longer-term success or growth within these types of entities, SMEs are undoubtedly crucial in providing innovative, economic stability to countries, given the sheer amount seen (Burns, 2016). The enhanced adoption of SMU, towards capturing and managing knowledge, shall heighten this belief. 
The plethora of social media platforms influence entrepreneurial behaviours and intentions (Nakara et al., 2012; Keegan et al., 2017). Many examples of social media are popular, especially amongst young people and provides a platform for businesses to enter the market and engage with consumers (Moe and Schweidel, 2014; Tsimonis and Dimitriadis, 2014).

Surrounding technological advancements have aided the progression of SMU, which encourage more 'real-time', purposive, responsive and dramatic change in an organisation's communication to the outside world. Furthermore, SMU assists in the marketing of an organisation's main tool towards acknowledging, creating and influencing its business activities, consumers and competitors: the ultimate marketing of their product or service.

Accordingly, the importance of social media as a promotional tool has long been accepted, although the potential impact of SMU in the KM is unclear (Ngai et al., 2015). However, a major part of an organisational strategy is increasing engagement through many social media platforms. Table 2 provides further insights into the most popular social media platforms:

Table 2. Popular Social Media Typologies

Platform

Facebook

\section{Description}

For most SMEs, Facebook provides a valuable channel to promote their products and services in order to maximise the effectiveness of a limited marketing budget of most SMEs. Drawing on this, customers would have access to products in real time and may pose questions about products. Facebook can be used as a means of brand awareness by encouraging other users to share information with their own networks

YouTube YouTube's revenue model relies on advertising through Google AdSense. In terms of usage, more than 400 hours of content were uploaded with an estimated 1 billion users watching approximately a billion hours of content daily.

Google As social media is essential for connecting with customers for SMEs, Google provides an online social network with an estimated 111 million users globally. The service allows users to create and update a personalised profile which offers the advantage of connectivity to a range of other Google products and services. Hence signalling clear potential for conducting its business this platform offers an increased reach through search engine optimisation.

Twitter Twitter as a social networking service allows users to post messages and interact through its micro-blogging site. Twitter boasts in excess of 319 million active users and is one of the most visited websites. For the SMEs, Twitter provides a very cost effective opportunity to reach a global audience in a fairly short space of time. It can be particularly powerful when attempting to build and develop a recognisable and personal brand or when promoting specific products.

Given that social media platforms such as those aforementioned are key tools in both B2B and B2C communication, due diligence must be exercised when organisations present their message as unwanted feedback and responses may come from salient stakeholders (Chua and Banerjee, 2013; Garrido-Moreno et al., 2015). On the other hand, in attempts to gather and manage valued knowledge, social media can be embedded horizontally within an organisation, encouraging lateral, 
entrepreneurially-minded individuals within the organisational context. This notion of organisational pluralism supports the contemporary business movement that includes increased employee involvement, increased motivation and encourages diversity and inclusion.

In increasing and exploiting organisational knowledge, social media management communicates with all level of stakeholders, meeting the organisations overarching objectives or mission statements (Ngai et al., 2015). As a result, a major part of an organisations corporate strategy is acknowledging, utilising and increasing engagement through a multitude of social media platforms.

SMU amongst SMEs is very much an interactive speculation to accumulate future, economic and opportunistic fortunes. SMU now forms part of our everyday activity, and recently, along with Wi-Fi availability, has jokingly been added to Maslow's well-known Hierarchy of needs concept model. Well-known, underlying management and entrepreneurial principles including planning, leading, organising, and co-ordinating are now enhanced with contemporary KM process, through the inviting mediums of SMU (Ritala et al., 2013; Kivipõld, 2015).

\section{Affirming Entrepreneurialism through SMU}

Entrepreneurship, especially within thriving SMEs, has long been viewed as the engine that drives innovation, promoting economic development. In capitalising on entrepreneurial skills, findings support the vital factor of research and development activities within organisationally-wide KM structures (Dalkir, 2013; Akhaven et al., 2016).

For many SMEs, and entrepreneurs alike, the most attractive strategic opportunity comes from entrepreneurial activity: turning an occasionally unclear idea into a detailed, viable opportunity (Burns, 2014; 2016). With this in mind, SMU becomes more prevalent towards decision making, marketing strategies, and wider consumer engagement (Ritala et al., 2013; Garrido-Moreno et al., 2015).

Innovation, with the aid of SMU, is the successful exploitation of considered and viable ideas (Lanskoronskis et al., 2009; Adner and Kapoor, 2010). Burns (2011: 66) lists '5 Types of Innovation' relevant to entrepreneurial success: an introduction of new or improved goods or services, an introduction of new process, the opening up of a new market, an identification of new sources of supply of raw materials, and the creation of new types of industrial organisation. As asserted previously through recent literature, innovation, which is now relevant to the SMU-led SME context, is likely to take place when the following properties are witnessed: they are comparably advantageous with existing activities and practice. Innovative ideas, based on managing crucial information, recovered SMU-led data and knowledge allow opportunities to be spotted, developed, created and implemented into the market, responding to given needs or desires (Figure 1).

Figure 1. The Realisation to Creation and Innovation Process 


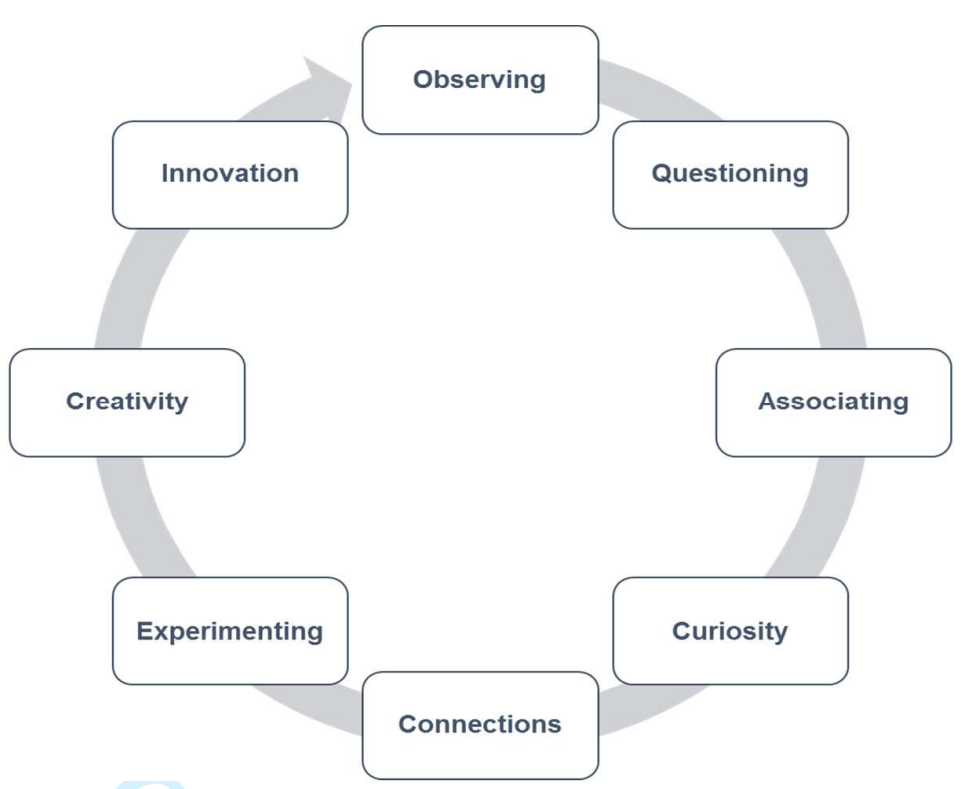

(Burns; 2016)

This concept is heightened by the ever-changing landscape that results from productive, yet volatile SMU. This notion of SME growth, associated with the proficient management of ideas, introduces a need shift in focus from the identification and management of creative individuals towards establishing and encouraging creative networks, involving productive social platforms, in coping with institutional and environmental complexities (Sigala and Chalkiti, 2015; Oostervink et al., 2016).

Notions of the 'innovation ecosystem' (Adner and Kapoor, 2010; Nambisan and Sawhney, 2011) or 'ecology of complex innovation' (Dougherty and Dunne, 2011) has been described as the distinctive innovation context where key change agents in the organisational to marketing cycle, including SME management, employees, customers and tertiary stakeholders are involved in changing and supporting innovation-led activities. Tidd and Bessant (2009) contribute by saying that one person's problem is another's opportunity, and this overriding nature of innovation and creativity is fundamentally entrepreneurship and its associated actions. Entrepreneurs, who know what to be alert for, and at what time, significantly increase their odds for overall success (Timmons and Spinelli, 2008). The required relationships between KM and desired innovation affects the organisational structure (see Figure 2) and directed strategy from decisions makers, through the appropriate management and utilisation of knowledge.

Figure 2. Tidd and Bessant's (2009) Innovation Process Model 
1

2

3

4

5

6

7

8

9

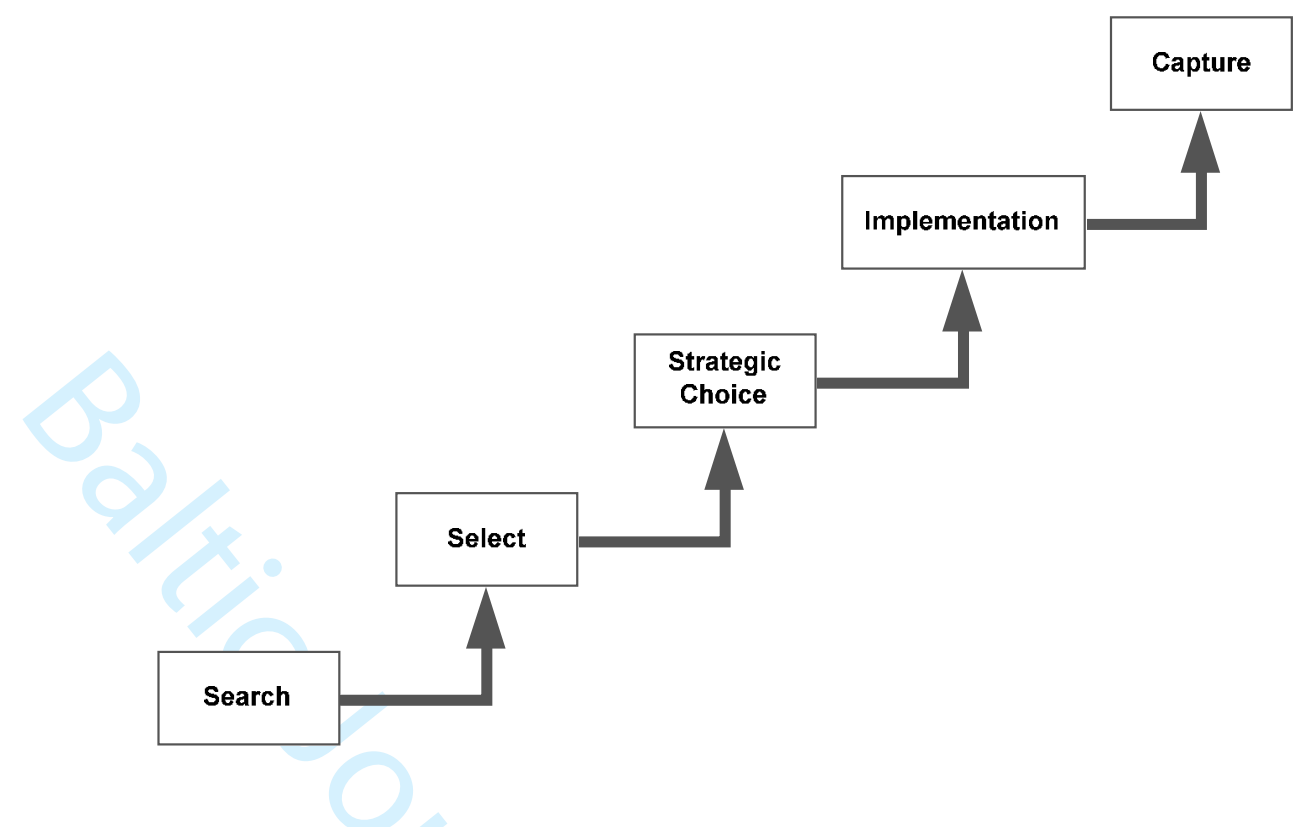

Processes involving KM systematically capture knowledge to capture markets (Bierly and Daly, 2007; Dalkir, 2013; Garrido-Moreno et al., 2015). Nonaka and Von Krogh (2009) note that there are two types of knowledge to be captured: explicit knowledge and tacit knowledge.

Explicit knowledge which is objective in nature, focuses on past events and expressed in systematic and formal language. It involves a sequential creation of digital activity which can be processed and transmitted easily. On the other hand, tacit knowledge which is subjective, is often difficult to communicate because it analogous in nature. It includes informal skills and expertise attained after a period of expertise. The increased utilisation of vital technological advances, and embedding such within the organisational structure present and its core processes heighten proficient $\mathrm{KM}$. Assessing the challenges in conceptualising organisational KM, including social and institutional perspectives, have been in abundance (Nonaka and Peltokorpi, 2006; Helms et al., 2017). Malhotra (2000) propose a guiding, sense-making KM model for business innovation, with view to practicing the accepted principles of the established KM paradigm.

Exploring and reviewing the wide and contemporary literature, within this pragmatic field, reinforces credible and prevalent assumptions of the acquisition and exploitation of knowledge (Adner and Kapoor, 2010; Chirico and Salvato, 2016; Helms et al., 2017). This can be said for the benefit of all businesses, from small enterprises to multinationals (see Gomezelj Omerzel et al., 2011 and Manfreda et al., 2015). Nevertheless, a prescriptive and strategic model is not clearly stipulated, defined or illustrated towards the entrepreneurial context. The findings of this paper shall constructively reason, conceptualise, and contribute to advancing this particular aspect of KM research, to progress entrepreneurial investigation and purposive commercial activity, which increases the opportunity for, and likelihood of, economic affluence.

\section{Approach}

This paper adopts a pragmatic, explanatory approach to include a wide population in the study, pursuing contextual evidence of the emerging KM and SMU nexus, as endorsed through business studies, mixed method literature (Mayring, 2007; Plowright, 2011). This included a survey containing twenty questions and subsequent, semi-structured interview process involving 34 businesses, and over 250 participants from the West of Scotland population, providing contextual evidence of SMU within SMEs. This allows for explantions of the descriptive data to be realised. Fuirthermore, with its high, industrious population, the West of Scotland presents a greater propability of contacting and investigating a broad multi-sector sample (see case study examples by Kivipõld, 2015 and Inkinen et 
al., 2015). Key results from the survey, along with extracts from the interviews conducted, are highlighted further within discussion, towards thematic reasoning.

Within the methodological spectrum of data collection strategy, mixing methods are the third paradigm (Tashakkori and Teddlie, 2003; Johnson and Onwuegbuzie, 2004) and have recently been defined as "a new star in the social science sky" (Mayring, 2007: 1). It rejects "traditional dichotomy between qualitative and quantitative methods" (Plowright, 2011: 2). Mixed methods research allows for data to be contextually explained, reasoned with consideration of many unqiue factors from the given population investigated, and "offers great promise for practicing researchers" (Johnson and Onwuegbuzie, 2004: 15).

Data was collected in the West of Scotland area, made possible by contacting local business leaders and entrepreneurial individuals who have had notable experience(s) of innovative KM management and entrepreneurial activity within SMEs. This contact was made by electronic mail (e-mail), telephone and online call (Skype) conversations. It was deemed imperative that a number of suitably, relevant participants were involved. The interviewees needed to possess the necessary credentials to contribute valuable information regarding KM integration within SMEs, entrepreneurial activity, and the effects of many factors affecting the efficient and effective use of KM processes.

The sample investigated was selected to not only capture descriptive, statistical data concerning their own working environments, but also recount anecdotal evidence of issues encountered within their sectors. This, of course, is subject to industrially, nationally, and internationally-led factors impacting on how, when, where and why they conduct their business operations in the manner they do. This proliferation of SMU is at the forefront of such recent factors that alter organisational market entry, shifting the paradigm of organisational values, behaviours and their surrounding, influential culture.

In total, 225 completed survey scripts were returned, from many various sources in companies from business parks and individuals that took part from the interview process. In total, 34 interviews were held, with participants including entrepreneurs, business owners and susequently financial and startup advisors. The table below charts respondents, per sector:

Table 3. Respondents by Sector

\begin{tabular}{lcc}
\hline \multicolumn{1}{c}{ Sector } & Survey Completions & Interview Participants \\
\hline Marketing & $52(23 \%)$ & $5(15 \%)$ \\
Engineering & $47(21 \%)$ & $6(18 \%)$ \\
Retail & $43(19 \%)$ & $12(35 \%)$ \\
Administration / Consultancy & $45(20 \%)$ & $7(21 \%)$ \\
Sole Trader & $38(17 \%)$ & $4(12 \%)$ \\
\hline Total & $\mathbf{2 2 5}$ & $\mathbf{3 4}$
\end{tabular}

Posing open-ended questions from a collective bank (see appendix 1), interviews were approximately 50 minutes in duration. Generally, a background and profile of the participant was sought before asking them to provide personal accounts of their entrepreneurial experience and anecdotes. As this was a semi-structured interview, questions asked during the course of the interview were a result of both pre-determined questioning (see appendix 1) and the responses given by the interviewee (see appendix 2). In practicing the promise of the mixed methodology, questions deduced from the literature were also posed during the interview phase, to allow participants to provide specific evidence from their experiences, which has shaped their organisational behaviours and perspectives.

Survey reliability was sought from reviewing current methodological practices within the field (see appendix 3). These examples showcased pertinent themes and critical considerations, as expressed within the question bank devised. Also, post-empirical contact was made with the participants to review the data recorded, to gain agreement and consent of its qualitiative content for analysis. 


\section{Findings}

The evidence highlights the benefits of SMU-assisted KM as a tool for SMEs. SMU enhances the administration of real-time knowledge, encouraging entrepreneurialism. However, longer-term costs of employing requisite personnel, and anticipated organisational restructuring, presents challenges. Due to increased use, reliance and potency of SM platforms, the roles of relevant professionals concerned with consumer and wider stakeholder engagement: marketing specialists, research and development teams, and advertising experts are centralised towards planning, leading and decision making roles. As outlined previously, the data is interpreted through a sequential-explanatory process, to constructively reason what was recovered (appendix 2). This practice allow for thematic mapping to be presented (Figures 3 and 4) that address the two core questions, and aids in the construction of this paper's RCIDTA model.

\section{What is the influence of social media in facilitating KM innovation in SMEs?}

In response to this first research question, most of the respondents agreed that the increase in 'market opportunity was apparent', given the proliferation of SM platforms and their variety.

"The variety of social media means we can realise greater market opportunities"

As a result, this has encouraged creatively-minded, innovative and entrepreneurial SMEs to take advantage of a predominately low-cost, easy-to-use, and wide reaching technology. This was particularly supported amongst marketing and engineering sector respondents. As the millennial generation enters the workforce, an increase in more SM-competent and technologically-savvy individuals was evident. This subsequently called, from those predominantly within administrative and consultancy responsibilities, for 'continuous screening and training' of relevant practitioners within the labour market.

"We do, however, have to conduct continuous screening and training to find the right people"

Over $80 \%$ of respondents are confident that KM can involve a wide variety of the workforce, encouraging greater stability and a pooling of resources. SMU is now strongly regarded as an effective way to swiftly market a brand, service or product within an SMEs planning and developmental infrastructure.

\section{"Social media channels allows us to bridge any gaps, and build a reputable stakeholder relationship"}

However, counter-productive organisational hierarchies that 'discourage increased employee involvement', and the related longer-term costs of employing requisite IT specialists, for innovative SMEs, presents on-going strategic, structural and human resource issues. These high costs of employing KM specialists, that can embed workable and lasting KM processes and activities, prevent 'efficient management of market knowledge' amongst SMEs and modest retailers.

"There needs to be efficient management of market knowledge that is regular, consistent and purposive"

Over $60 \%$ believe that SMU has increased the organisation's awareness of specific stakeholder and consumer profiles. Respondents that represent the marketing and retail sectors acknowledged the volatility of changing consumer trends and fluctuating market conditions.

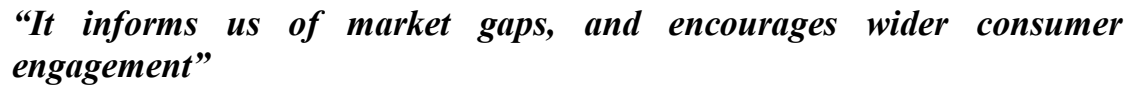


Stakeholder awareness, in gathering key knowledge, was regarded as essential to respondents in sourcing relevant information, and maintaining cost and operational efficiencies. This informs and encourages purposeful brand building, and a succinct competitive advantage within the market. In turn, entrepreneurial intentions are expectantly raised, as wider audiences are reached.

Figure 3. Thematic Map (Q1)

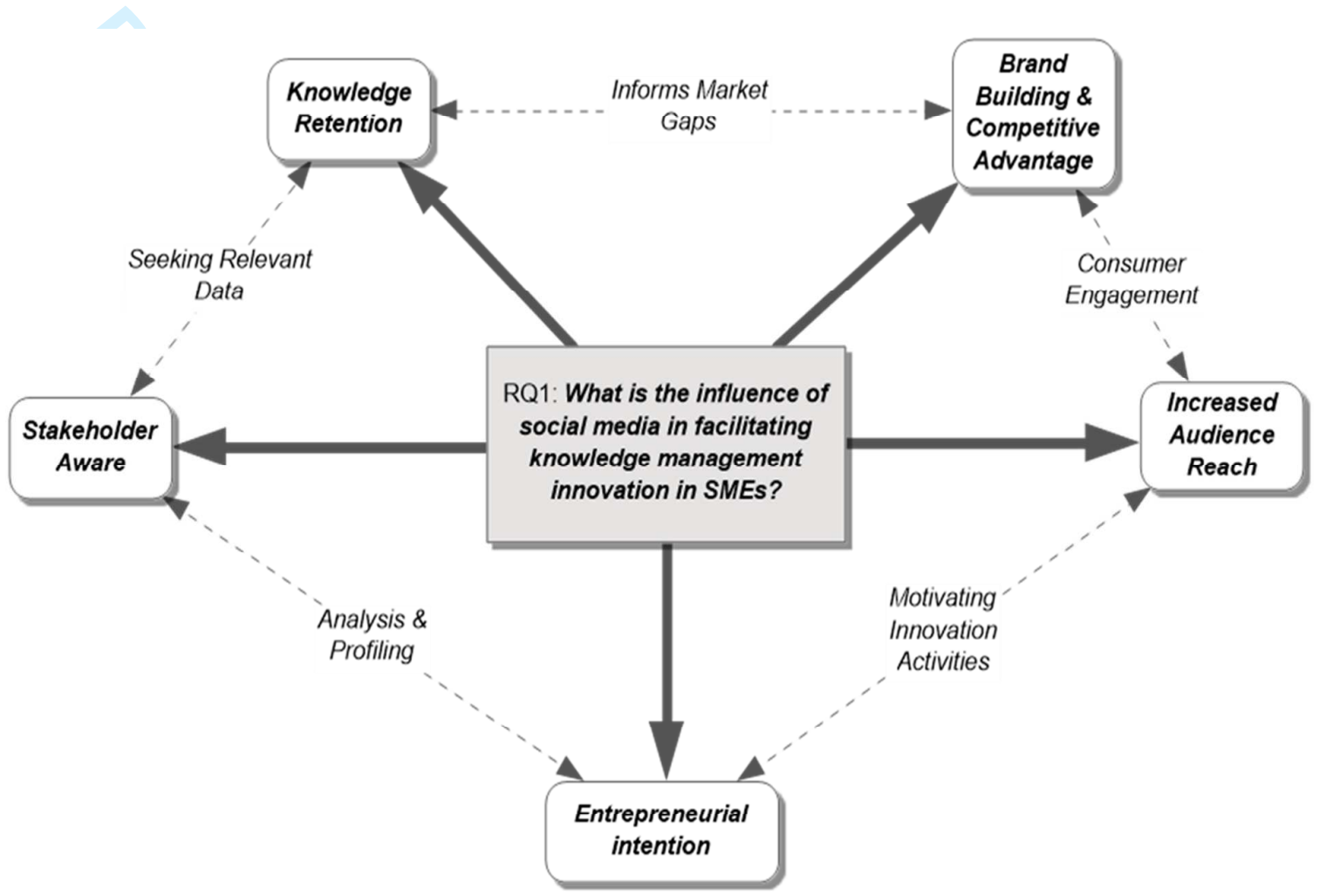

Over $75 \%$ of respondents believe that SMEs use of SMU encourages better customer services. Respondents such as sole traders stated that increased use of SMU allowed their SME to engage more 'regularly', 'consistently' and 'purposefully' with consumers.

\section{"I have found it to be highly motivating for my staff, and encourages innovative activities"}

This consistent contact and communication, which through SMU is instantaneous, improved the 'stakeholder relationship' and allowed their respective SMEs to resolve particular consumer issues.

\section{"We can adequately build our brand, and realise a distinct competitive advantage in the market"}

Over $80 \%$ of the respondents feel that they promote an entrepreneurial culture within their SMEs. However, disparities are evident between this paradigm-shifting culture effecting internal, operational behaviours and customs (engineering and administrative duties) or market-facing activities (retail and small business). The advent of social media alters this resource allocation need of entrepreneurs and is now 'firmly part' of an entrepreneur's product or small business 
infrastructure. The evidence from the interview phase showed that the marketing and innovation of an idea, as part of the entrepreneurs' development, can be facilitated with the 'assistance of SMU'.

"Social media enhances the level of our organisational knowledge which informs planning and operational activities"

Interesting and productive 'blogs' is but one example where the entrepreneurial journeys of aspiring businesspeople are seen online.

"This consistent communication through SMU is instantaneous, and allows us to show that we care about what we do"

Sectors consistently engaging with consumers reacted positively to questions concerning the influence of social media, and its aiding of enhancing organisational knowledge of given sectors and informing planning and operational activities.

\section{How can SMEs shape the implementation of social media towards new ways of productivity?}

The greater choice of social media platforms and the fact that it can be managed on small devices such as smartphones, encourages a certain degree of freedom, short-term, from other start-up related issues (i.e. work space, funding).

"When you appreciate the benefits of social media, you just have to adapt and ensure your brand is displayed through all available online channels"

These market-facing industries confirm that SMU appeals to a wide audience and opens relevant customer bases. It allows users to assess these customer bases and develop within them.

"Our organisational vision is now based on what we can now do online, and what information we can source about what we do, and how we can do it better"

Respondents spoke of how carefully implemented KM greatly increased awareness of their business operations, personnel requirements and resource allocation.

"We see the impact on our financial, human, social and physical resources"

An entrenched system encouraged HR and business planning, in acquiring financial, social, physical and human capital. This enhanced resource maximisation and product delivery, as recounted during the interviews, directs SMEs towards penetrative and new market strategies.

"Efficient management of our market research directly informs how we contact and communicate existing and new customers - it is exciting times!”

Around $65 \%$ believe capturing and retaining knowledge is a core requirement towards the sustainability of an SME. Respondents and interview participants acknowledge that the acquisition of knowledge within their given sector is as valuable to their organisation as 'financial, human, social and physical capital'.

"The company gets to express itself better, with the variety of platforms and ways in which we can connect" 
Entrenched KM processes within their SMEs were said to have motivated the workforce towards 'relevant activities', due to there being reliable data and information from precise stakeholder groups within the market.

"Although not every platform is helpful, we try to be as effective and as practical as possible. We listen to our customers, as being online, they cannot be avoided or ignored"

Unsurprisingly, this also had an effect on the 'creation', 'innovation' and 'production' phases of SME product and service development.

“Fresh ideas, fresh people, fresh processes, is what will make our company tick in the social media age"

Around $40 \%$ of respondents, those in senior managerial or supervisory positions, believe that they are involved in decision making, based on externally sourced market knowledge. Many respondents of the survey, along with interview participants, stated that although aware of KM processes, they were not 'primarily' or 'occasionally' involved in decision making.

"Times change, so we must change - increasing the profitable capabilities of our company is what we must assess"

Some added that it was a concern that decision making could potentially 'stifled' creativity, and prevent both entrepreneurial 'vision' and 'expression'.

Figure 4. Thematic Map (Q2) 


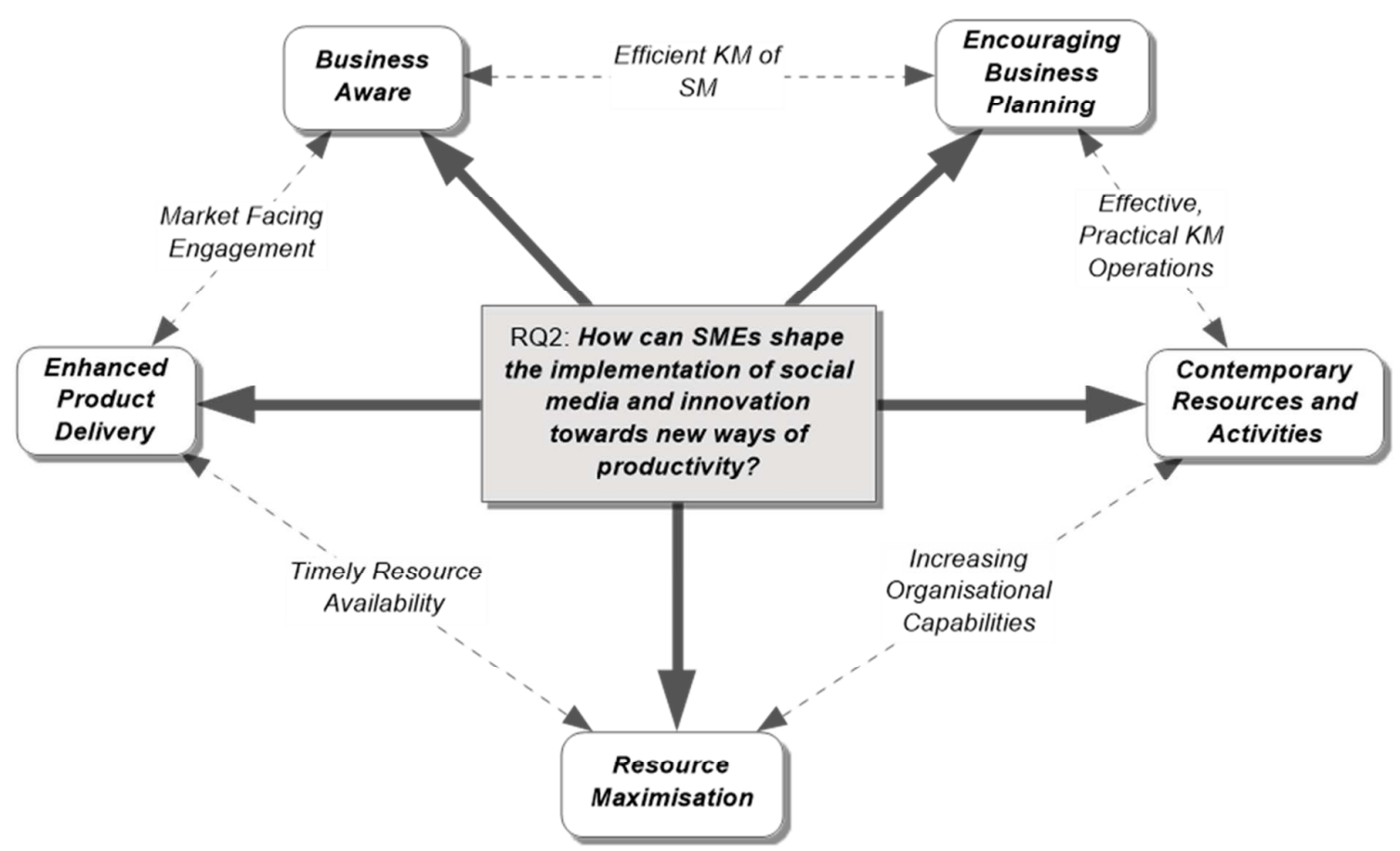

Over $75 \%$ of the survey respondents believe that entrepreneurialism is a key driver in the work that you perform within your SME. Along with the above result, interviewees highlighted that the market requires SMEs to think 'laterally' and 'productively', to keep apace of competition, industrial advancements and macro-economic fluctuations. This shift from basic business fundamentals, to implementing and solidifying creative and innovative ideals into the core of organisational objectives, has reshaped the SMEs investigated in this paper.

\section{"We experience a certain degree of freedom to really show what we are all about”}

Although bureaucratic concerns were established, the nature of SMU brings closer the consumer's needs and desires, informing SMEs of the marketplace and alerting them to ongoing economic, political and social considerations.

SMU influences habitual creativity amongst innovative industries, increasing self-awareness in the market and confidence in both the entrepreneur and consumer. This alerts management to introducing more explicit KM processes. SMU streamlines business planning by reducing doubt in both the product and the customer base. Through competent KM systems and processes, SMEs instigate growth by creating new business activities and projects, which in turn create jobs, intensify competition, and subsequently increase productivity through reactionary change.

In order to survive, there is a strong and recurring $21^{\text {st }}$ century argument, from business leaders, entrepreneurs, and academics, that SMEs must develop more habitual, open innovation models that directly respond to market fluctuations, technological advancements and changing consumer preferences. This includes the redefining of their personnel, resource, economic and logistic infrastructures. This allows for economically efficient, and managerially effective decisions to be actioned. With this in mind, it is crucial to gain a conceptual understanding of an SMEs use of KM processes, which are hugely significant concerning national and international enterprise in the $21^{\text {st }}$ century, towards continuous and profitable innovative activities.

In triangulatory analysis of these survey and interview findings, pertinent themes arose from the interview phase of the empirical study. These include KM Processes and Information Exploitation: Organisational Strengthening, SMU and Associated Tools: Technologically-ready, SMEs and 
Entrepreneurialism: SME Development. The next section frames these reasoned themes towards constructing a valuable model to equip SMEs with an SMU-assisted KM.

\section{Establishing An Entrepreneurial Process for Purposive SMU}

Applicable theories of contextualised KM, habitual entrepreneurship practices and repsonsive SMU are now established, contemporary forerunners towards performance (Inkinen et al., 2015; Scuotto et al., 2017a; 2017b). However, the majority of studies exploring the growth implications of different entrepreneurial characteristics appear to be partial, lacking a structural framework towards best practice (Dalkir, 2013). This leads to particular uncertainty concerning the factors to which these varying entrepreneurial characteristics influence firm performance, size and competitive advantage. While the above discourse supports Nonaka and Takeuchi's (1999) view that enterprises are innovative when they create new information through interactions with their environment, accomplishing this would require SMEs complementing KM practices with social media. SMEs may also fail to tap into the opportunities available within their business.

This paper highlights three critical themes, accentuating the SMU and KM nexus. Subthemes, or contextual factors witnessed from the thematic, analytical process, are realised within appendix 2. These three critical themes are: KM Processes \& Information Exploitation, SMU \& Associated Tools and SMEs \& Entrepreneurialism. Figure 5, a novel illustration from this paper, displays these critical themes, post-explanatory process, detailing practical considerations for SMEs, along with displaying the fundamental rationale for entrenched KM processes: 
Figure 5. The KM-SMU Nexus within SME Contexts

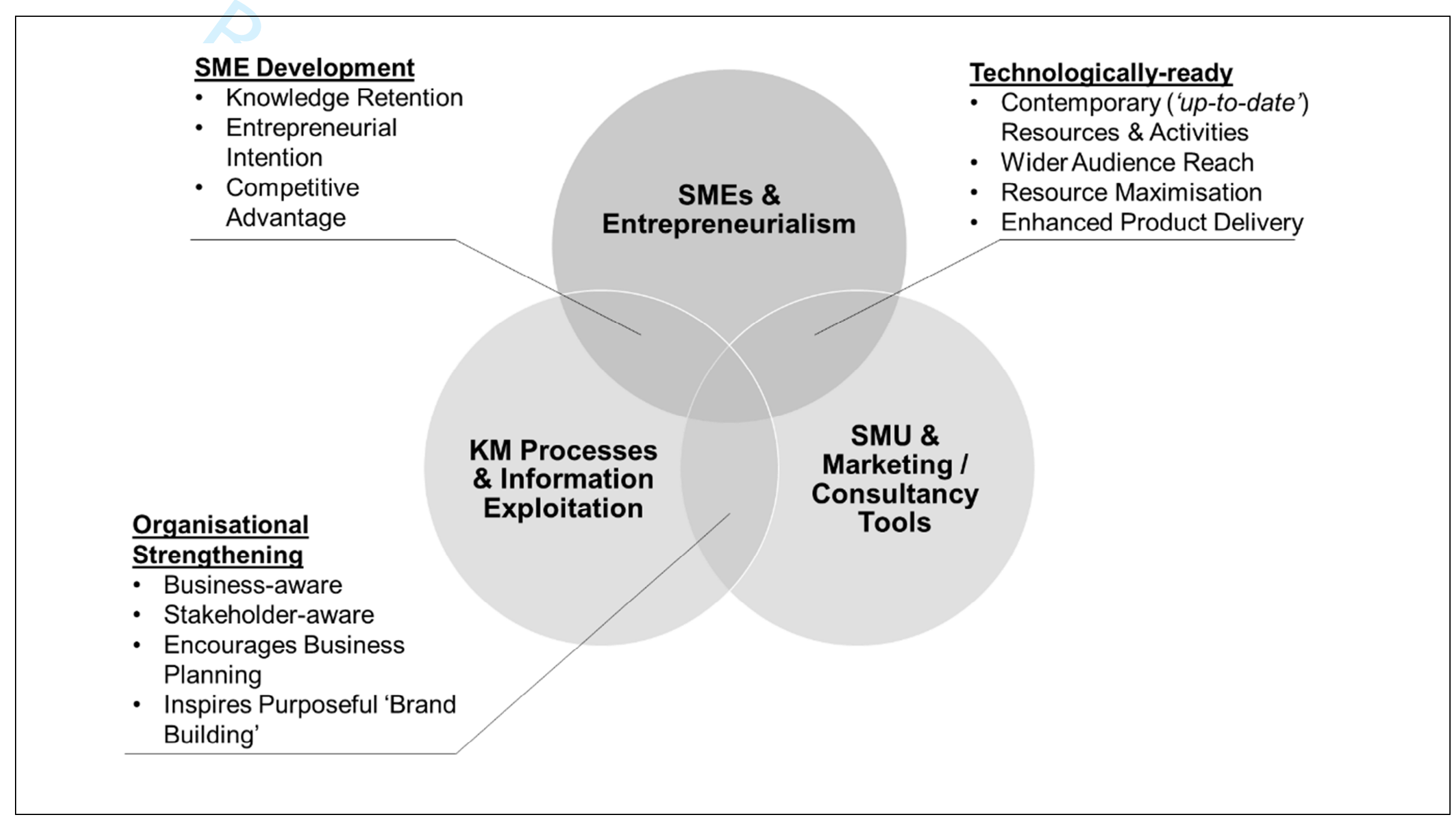


From the evidence, a systematic framework towards purposeful KM, within the context of SMEs, to assert entrepreneurial behaviour and sustained organisation growth is constructed. This paper prescribes an original, strategic RCIDTA model (Figure 6), established from the empirical data of this paper, that advances conceptual assertions made within progressive SM-related, KM literature (see Bharati et al., 2015; Garrido-Moreno et al., 2015; Inkinen et al., 2015; Kivipõld, 2015). RCIDTA progresses innovative ideologies that promotes reflective and stead-fast change within the organisation. This novel, systematic approach underpins the connectivity between KM practices and reasoned, astute entrepreneurial behaviours.

SMU instills greater confidence to develop entrepreneurial traits by engaging with potential and present stakeholders. Extending this point in relation to innovation, we maintain that developing innovation within SMEs can be achieved through six phases of SMU-led KM: Research, Concept, Institutionalise, Develop, Target, and Advance.

We define the RCIDTA model as a process of investigating, reflecting and institutionalising KM using social media platforms to facilitate innovation. The use of RCIDTA within SMEs can be used in improving the knowledge eco-systems of SMEs, providing for innovation and sustained growth. 
Figure 6. The RCIDTA Model towards SM-led Entrepreneurial Exploitation

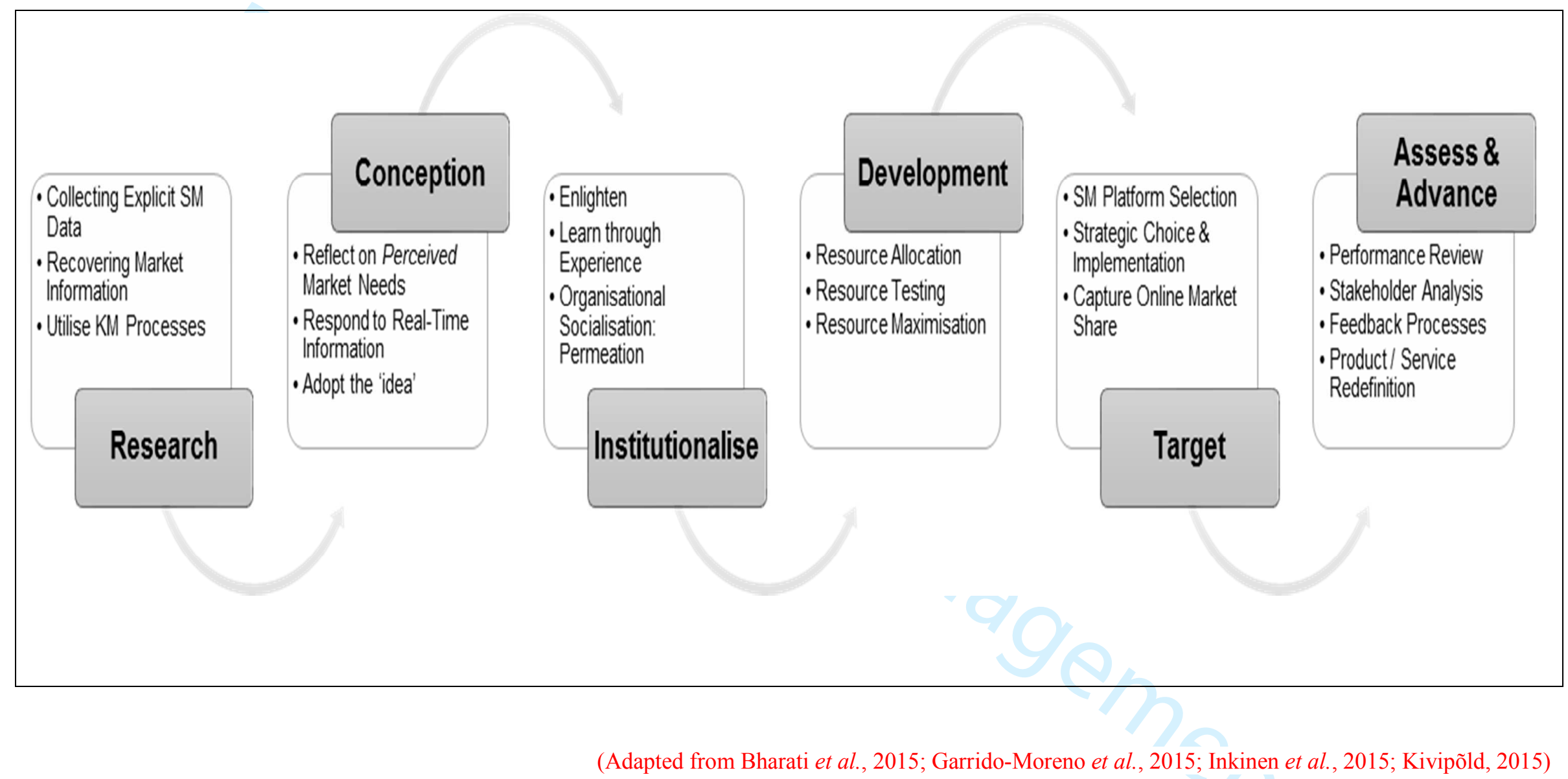




\section{Research}

Reflected within the interviews conducted, the first phase chiefly highlights the need to attain market data and stakeholder information. Greater brand awareness within the market is vital, and this collection of explicit SM data allows for the execution of appropriate, efficient, and effective resources and capital. This of course presents internal responsibilities, concerning the appropriate allocation of duties towards research development, consumer relations, and related market analysis. Organisations must embrace social, cultural, and technological differences (Ardichvili et al., 2006; Lanskoronskis et al., 2009; Bharati et al., 2015).

\section{Conception}

Anticipating requisite collection of data, from within the SME and of stakeholder satisfaction, the organisation can suitably reflect on the needs of the market and establish strategic options. Asserting and adopting the next 'big idea', towards prosperity and growth is addressed. Subsequently, greater efficiency in the allocation of the SMEs product or service development, recruitment, and SMU-led market penetration can be devised. As with gathering this information, during the first phase, the conception phase is of critical importance in relating with the market and its consumers, competitors, and international ventures (Chua and Banerjee, 2013; Garrido-Morena et al., 2015). Ideas that are devised at this phase respond to real-time information with long-lasting effective strategy: a concern of participants.

\section{Institutionalise}

The permeation of new and innovative ideas socialises the intention of the SME, as subsequent objectives permeate throughout the organisation. This phase requires entrepreneurial SMEs to underline their strategic, operational, and entrepreneurial intentions (Burns, 2014; 2016; Kivipõld, 2015). It is expected that this is actioned through revised and efficient process, with an onus on achieving notable profit and competent budgetary forecasting. Crucially, there is the opportunity for the culture of the SME to positively realign towards the reactive operations, influenced by phases 1 and 2, and an opportunity to learn through past experiences which indeed led to market research and institutional review (Harrison and Leitch, 2005; Inkinen et al., 2015; Chirico and Salvata, 2016).

\section{Development}

As the organisation adopts the new entrepreneurial ideology, renewed processes, and information inherited, duties and responsibilities are allocated. Scenario analysis or testing of new products and services aim to reduce risk towards the SMEs reputation. Closer relationships with customers and partners are established in understanding what resources and capabilities of the SME must be adopted, learned, and improved (Lumpkin and Lichtenstein, 2005; Zhao et al., 2011). This could involve the previous rhetoric, activites, product attributes such as costing and quality, as well as logistical and distributive issues. At this point, the level of competitive advantage can be gauged and addressed through online channels (Bierly and Daly, 2007; Ellison, 2007).

Target

Towards the latter, market-penetrative phases of the model, appropriate SMU is scrutinised and selected (Bolotaeva and Cata, 2010; Scuotto et al., 2017b). Current or new markets are detailed to vindicate decisions. Managers, with caution, ascertain increased online connectivity and implementation, which includes the wider stakeholder (Manfreda et al., 2015; Scuotto et al., 2017a). In attaining the desired market share, a review of collected data, which by now is formally integrated and entrenched within new objectives, must be periodically updated in refining brand representation. 
Quantifying and forecasting of potential financial reward, as well as the consequences of their performance should be understood.

\section{Assess and Advance}

Respective to the given product or idea cycle, adequate performance review must take place in order to ascertain the SMEs entrepreneurial and innovative performance and stakeholder satisfaction, given the entities growth, expanded customer base and opportunities ventured (Naldi and Davidsson, 2014). This comprehensive stakeholder analysis should follow similar procedures to that of the first phase, as a feedback process informs the organisation of any incremental or substantial changes required (Gomezelj Omerzel et al., 2011). This may involve product or service redefinition, replacement or enhancement. In advancing the SMEs use of SM platforms, an awareness of customer loyalty, trust, and general perspectives of the organisation should be outlined, as specified per given operation (Hsu et al., 2007; Choi et al., 2008).

RCIDTA formalises progressions within the study of conceptualised KM (Gomezelj Omerzel et al., 2011; Ritala et al., 2013), incorporating understandings of SMEs use of SM platform. Components of an innovative organisation include harnessing, sharing and socialising an entrepreneurial vision, the diverting of leadership, a structure that encourages a creative climate, the involvement of innovative individuals, with the purpose of learning from the external environment.

\section{Implications of RCIDTA}

In recent years, SMU is the norm within SMEs. It is now assumed that people regularly use a number of social media applications as part of their everyday lives. Teenagers, for example, can spend around nine hours a day on SM platforms (Social Media Today, 2017). They engage with friends, family, work colleagues and businesses that they may have been consumers with using these forms of communication. Therefore, it is fast becoming second nature that people, as consumers, contact businesses to praise or complain about the products or services on offer. However, for businesses, SMU must be scrutinised, tested and assessed.

The RCIDTA model highlights core issues concerning the exploitation of sector-specific KM towards entrepreneurial exploitation, including the impact of renewed $\mathrm{KM}$ processes on organisational strategy, firm structure, brand formation, fiscal and personnel resource allocation, and market share, as expressed by survey and interview participants.

This paper introduces, through RCIDTA, opportunities for SMEs to systematically build and maintain prosperous and knowledge-driven ecosystems. Firstly, this paper's proactive model embeds an innovation, KM culture by encouraging consumer-focussed action, based on received data, information and knowledge, to introduce novel and competitive solutions into the market. Secondly, an implied decentralisation of leadership and management roles are inevitable, as the process model requires the input and influence of individuals across and along organisational structures. With the spirit of problem solving with real-time solutions in mind, notions of autocratic, 'top-down' management are unrealistic, misguided, and counter-productive. Thirdly, as the process relies on, and is informed by, market research and external information, knowledge is captured and managed through continuous and obliged engagement with all relevant and potential stakeholders.

The pragmatic study conducted within this paper expands on previous literature and informs, within the SME context, of the critical issues faced. The survey component of this paper's study captures initial, preliminary data which should be investigated further towards understanding, with a greater population, the particular thematic issues addressed here. We are also aware that our empirial findings population sample size may have been limited by a paucity in sample size. Hence in order to overcome this limitation, further study may provide a new dimension by increasing the sample size population. This, we contend would establish a distinct picture of KM in relation to social media usage. Our recommendations also encourage futher research in exploring the downside of SMU. 
However, the anecdotal evidence within this paper contributes to the systematic RCIDTA model which responds to needs and desires of contemporary organisations. RCIDTA embraces and combines current, and fashionable entrepreneurial tendencies within SMEs with a systematic process upon which operational objectives are contemporarily attained.

We argue, given the importance of SMU in our daily lives, its application towards complementing KM must be examined. Our discovery is that social media, when applied to KM, provides real entrepreneurial value. This is evident in the light of large companies that have become innovative through an effective usage of social media technologies. As social media continues to change the way business is conducted, most of these large companies are moving beyond towards a more systematic and strategic application of social media to KM.

Managing knowledge involves the generating and acquiring of new knowledge, identifying and codifying existing knowledge, storing and retrieving knowledge, occasionally sharing and distributing this knowledge, and exploiting and embedding knowledge towards products and services. SMU undoubtedly enables people, and organisations, to visualise ideas, create opportunities, share information, expressing these ideas to a universal audience. Conducting market research, instructs structured communication across the organisation, engagement with consumers with given promotions, discounts, and loyalty relationships. The process creates a feedback mechanism: recognising consumer opinion, preferences and information, to build organisational knowledge about and for consumers.

\section{Conclusion}

This paper argues that contemporary KM, through SMU, facilitates the interactions between managers, employees, and external stakeholders to execute innovative processes towards entrepreneurial expectations. The paper's systematic model fosters a practical, phased process that assists SME management and business leaders in organising their workforce to manage, develop and capture knowledge within targeted marketplaces.

Empirical findings within this paper strongly indicate that SMEs are aligning their use of SM platforms in marketing, advertising and communicating their products and services to consumers to that of long standing KM activities. Additionally, this paper highlights the recent and growing approach and behaviours of SMEs using social media when entering their given market. SMU, its effectiveness and cost efficiency gives way to further start-ups being established. Furthermore, surrounding this $21^{\text {st }}$ century phenomena are issues concerning brand formation, resource allocation and market share through such efficient technological applications. Anecdotal evidence reinforces the widely-held argument that the role of KM is crucial in the context of contemporary organisational strategy, the reconfiguration of organisational structure and allocated resources within SMEs, strengthening brand image.

In essence, this paper contributes to KM's core value of managing information with a progressive model that introduces contemporary SME qualities such as the embedding of an entrepreneurial culture, decentralisation of leadership, and encouraging socially-responsive and entrepreneurial activities.

A direct result of research such as this consults SMEs and its infrastructure. Benefits of SMU are now widely witnessed in entrepreneurial settings. However, greater empirical study is needed across many demographs.

This paper shows that the link between SMU, entrepreneurial intent and success is stronger than first assumed. SMU increases intentions as these technological platforms are an easy way to get consumer 'feedback' on your product service or brand. Furthermore, widespread examples of SMU and its effects on aspiring and SMEs can display significant profiles and perspectives of individuals as related academic literature advances. Rooted in innovative practices and an overwhelming entrepreneurial vision, as witnessed from ambitious SMEs, this framework benefits innovative ideologies and encourages proactive engagement with all members of immediate ecosystems. 


\section{References}

- Adner, R. and Kapoor, R. (2010) "Value creation in innovation ecosystems: how the structure of technological interdependence affects firm performance in new technology generations", Strategic Management Journal, Vol. 31 No. 3, pp. 306-333.

- Akhavan, P., Ebrahim, N.A., Fetrati, M.A. and Pezeshkan, A. (2016), "Major trends in knowledge management research: a bibliometric study", Scientometrics, Vol. 107 No. 3, pp.1249-1264.

- Ardichvili, A., Maurer, M., Li, W., Wentling, T. and Stuedemann, R. (2006) "Cultural influences on knowledge sharing through online communities of practice", Journal of Knowledge Management, Vol. 10 No. 1, pp. 94-107.

- Bailetti, T. (2012), "Technology entrepreneurship: overview, definition, and distinctive aspects", Technology Innovation Management Review, Vol. 2 No. 2, p.5.

- Bharati, P., Zhang, W. and Chaudhury, A. (2015), "Better knowledge with social media? Exploring the roles of social capital and organizational knowledge management", Journal of Knowledge Management, Vol. 19 No. 3, pp.456-475.

- Bierly, P. E. and Daly, P. S. (2007) "Alternative knowledge strategies, competitive environment, and organizational performance in small manufacturing firms", Entrepreneurship Theory and Practice, Vol. 31 No. 4, pp. 493-516.

- Bolotaeva, V. and Cata, T. (2010) "Marketing opportunities with social networks", Journal of Internet Social Networking and Virtual Communities, pp. 1-8.

- Burns, P. (2014), New Venture Creation: A Framework for Entrepreneurial Start-Ups, Palgrave Macmillan, Basingstoke.

- Burns, P. (2016), Entrepreneurship and Small Business: Start-up, Growth and Maturity, $4^{\text {th }}$ ed. Palgrave Macmillan, Basingstoke.

- Chirico, F. and Salvato, C. (2016) "Knowledge internalization and product development in family firms: When relational and affective factors matter", Entrepreneurship Theory and Practice, Vol. 40 No. 1, pp. 201-229.

- Choi, Y. R., Lévesque, M. and Shepherd, D. A. (2008) "When should entrepreneurs expedite or delay opportunity exploitation?", Journal of Business Venturing, Vol. 23 No. 3, pp. 333-355.

- Chua, A.Y. and Banerjee, S. (2013), "Customer knowledge management via social media: the case of Starbucks". Journal of Knowledge Management, Vol. 17 No. 2, pp. 237-249.

- Creswell, J. W. and Plano Clark, V. L. (2011), Designing and Conducting Mixed Methods Research, 2nd ed. SAGE Publications Ltd, London.

- Dalkir, K. (2013), Knowledge Management in Theory and Practice, Elsevier ButterworthHeinemann, Boston.

- Dougherty, D. and Dunne, D.D. (2011), "Organizing ecologies of complex innovation", Organisation Science, Vol. 22 No. 5, pp. 1214-1223.

- Ellison, N. B. (2007) "Social network sites: Definition, history, and scholarship", Journal of Computer $\square$ Mediated Communication, Vol. 13 No. 1, pp. 210-230.

- Garrido-Moreno, A., Lockett, N. and Garcia-Morales, V. (2015) "Exploring the role of knowledge management practices in fostering customer relationship management as a catalyst of marketing innovation", Baltic Journal of Management, Vol. 10 No. 4, pp. 393-412.

- Gomezelj Omerzel, D., Antončič, B. and Ruzzier, M. (2011) "Developing and testing a multidimensional knowledge management model on Slovenian SMEs", Baltic Journal of Management, Vol. 6 No. 2, pp. 179-204.

- Hamoud, M.W., Tarhini, A., Akour, M.A. and Al-Salti, Z. (2016), "Developing the main knowledge management process via social media in the IT organisations: A conceptual perspective". International Journal of Business Administration, Vol. 7 No. 5, pp. 49.

- Hanna, R., Rohm, A. and Crittenden, V. L. (2011), "We're all connected: The power of the social media ecosystem", Business Horizons, Vol. 54 No. 3, pp. 265-273. 
- Harrison, R. T. and Leitch, C. M. (2005) "Entrepreneurial learning: Researching the interface between learning and the entrepreneurial context", Entrepreneurship Theory and Practice, Vol. 29 No. 4, pp. 351-371.

- Harrysson, M., Metayer, E. and Sarrazin, H. (2012), "How 'social intelligence'can guide decisions", McKinsey Quarterly, Vol. 4, pp.81-89.

- Helms, R., Cranefield, J. and van Reijsen, J. (2017), "Social Media and Knowledge Management: A Perfect Couple", In Social Knowledge Management in Action, (pp. 1-13). Springer International Publishing.

- Hsu, M. H., Ju, T. L., Yen, C. H. and Chang, C. M. (2007) "Knowledge sharing behavior in virtual communities: The relationship between trust, self-efficacy, and outcome expectations", International Journal of Human-Computer Studies, Vol. 65 No. 2, pp. 153-169.

- Inkinen, H. T., Kianto, A. and Vanhala, M. (2015) "Knowledge management practices and innovation performance in Finland", Baltic Journal of Management, Vol. 10 No. 4, pp. 432-455.

- Johnson, R. B. and Onwuegbuzie, A. J. (2004), "Mixed methods research: A research paradigm whose time has come", Educational Researcher, Vol. 33 No. 7, pp. 14-26.

- Kaplan, A. M. and Haenlein, M. (2010) "Users of the world, unite! The challenges and opportunities of Social Media", Business Horizons, Vol. 53 No. 1, pp. 59-68.

- Keegan, B.J. and Rowley, J. (2017), "Evaluation and decision-making in social media marketing", Management Decision, Vol. 55 No. (1), pp. 15-31.

- Khodakarami, F. and Chan, Y.E. (2014), "Exploring the role of customer relationship management (CRM) systems in customer knowledge creation", Information \& Management, Vol. 51 No. 1, pp.27-42.

- Kivipõld, K. (2015) "Organizational leadership capability-a mechanism of knowledge coordination for inducing innovative behaviour: A case study in Estonian service industries", Baltic Journal of Management, Vol. 10 No. 4, pp. 478-496.

- Kuemmerle, W. (2002) "Home base and knowledge management in international ventures". Journal of Business Venturing, Vol. 17 No. 2, pp. 99-122.

- Lanskoronskis, M., Ramoniene, L. and Barsauskas, P. (2009) "Innovative research management as a tool for institutional competitiveness". Baltic Journal of Management, Vol. 4 No. 3, pp. 353368.

- Lenihan, H., Andréosso-O'Callaghan, B. and Hart, M. (2010), "SMEs in a Globalised World: Survival and Growth Strategies on Europe's Geographical Periphery”, Edward Elgar Publishing Ltd, London.

- Leonardi, P.M. (2017) "The social media revolution: Sharing and learning in the age of leaky knowledge". Information and Organisation, Vol. 27 No. 1, pp. 47-59.

- Lumpkin, G. T. and Lichtenstein, B. B. (2005) "The role of organizational learning in the opportunity $\square$ recognition process". Entrepreneurship Theory and Practice, Vol. 29 No. 4, pp. 451-472.

- Malhotra, Y. (2000), "Knowledge Management and New Organization Forms: A Framework for Business Model Innovation”. Information Resources Management Journal, Vol. 13 No.1, pp. 514.

- Manfreda, A., Buh, B. and Indihar Štemberger, M. (2015) "Knowledge-intensive process management: a case study from the public sector", Baltic Journal of Management, Vol. 10 No. 4, pp. 456-477.

- Michaelidou, N., Siamagka, N. T. and Christodoulides, G. (2011), "Usage, barriers and measurement of social media marketing: An exploratory investigation of small and medium B2B brands", Industrial Marketing Management, Vol. 40 No. 7, pp. 1153-1159.

- Nakara, W. A., Benmoussa, F. Z. and Jaouen, A. (2012), "Entrepreneurship and social media marketing: evidence from French small business", International Journal of Entrepreneurship and Small Business, Vol. 16 No. 4, pp. 386-405.

- Naldi, L. and Davidsson, P. (2014) "Entrepreneurial growth: The role of international knowledge acquisition as moderated by firm age", Journal of Business Venturing, Vol. 29 No. 5, pp. 687703.

- Nambisan, S., Sawhney, M., (2011), "Orchestration processes in network-centric innovation: evidence from the field", Academy of Management Perspectives, Vol. 25 No. 3, pp. 40-57. 
- Ngai, E.W., Tao, S.S. and Moon, K.K. (2015), "Social media research: Theories, constructs, and conceptual frameworks", International Journal of Information Management, Vol. 35 No. 1, pp. $33-44$.

- Nickols, F. W. (2000), "The knowledge in knowledge management", In Cortada, J.W. and Woods, J.A. (Eds) The knowledge management yearbook 2000-2001, pp. 12-21. ButterworthHeinemann, Boston, MA.

- Nonaka, I. and Peltokorpi, V. (2006), "Objectivity and subjectivity in knowledge management: a review of 20 top articles", Knowledge and Process Management, Vol. 13 No. 2, pp.73-82.

- Nonaka, I. and Takeuchi, H. (1999), "The knowledge-creating organization. As Japanese companies create the dynamics of innovation", The creator of knowledge: How Japanese companies create the dynamics of innovation.

- Nonaka, I. and Von Krogh, G. (2009), "Perspective -Tacit knowledge and knowledge conversion: Controversy and advancement in organizational knowledge creation theory". Organisation Science, Vol. 20 No. 3, pp. 635-652.

- Nonaka, I., Toyama, R. and Nagata, A. (2000), "A firm as a knowledge-creating entity: a new perspective on the theory of the firm", Industrial and Corporate Change, Vol. 9 No. 1, pp. 1-20.

- Nonaka,I. and Takeuchi, H. (1995), The Knowledge Creating Company, Oxford University, New York.

- Nonaka,I., Toyama, R.and Byosiere, P.(2001), “A theory of Organizational Knowledge Creation: Understanding the Dynamic Process of Creating Knowledge", In Dierkes, M., Berthoin A., Child, J. and Noanaka, I. Handbook of Organizational Learning and Knowledge, New York, pp 491-517.

- Nunes, M.B, Annanisingh, B. and Eaglestone, B. (2006), "Knowledge Management issues in knowledge-intensive SMEs", Journal of Documentation, Vol. 62 No. 1, 2006 pp. 101-119.

- Oostervink, N., Agterberg, M. and Huysman, M. (2016), "Knowledge Sharing on Enterprise Social Media: Practices to Cope With Institutional Complexity", Journal of Computer $\square$ Mediated Communication.

- Peltier, J. W. and Scovotti, C. (2010), "Enhancing entrepreneurial marketing education: the student perspective", Journal of Small Business and Enterprise Development. Vol. 17 No. 4, pp. 514-536.

- Ritala, P., Henttonen, K., Salojärvi, H., Sainio, L. M. and Saarenketo, S. (2013) "Gone fishing for knowledge? The effect of strategic orientations on the scope of open knowledge search". Baltic Journal of Management, Vol. 8 No. 3, pp. 328-348.

- Sam, Y. and Cai, Y. (2014), "A Study on the Use of Social Media to Understand Consumer Preference: The Case of Starbucks". International Journal of Management and Business Research, Vol. 5 No. 3, pp.207-214.

- Sasi, V. and Arenius, P. (2008), "International New Ventures and Social Networks: Advantage or Liability?", European Management Journal, Vol. 26, pp. 400-411.

- Schultze, U. and Stabell, C. (2004), "Knowing What You Don't Know? Discourses and Contradictions in Knowledge Management Research", Journal of Management Studies, Vol. 41, pp. 549-573.

- Scuotto, V., Del Giudice, M. and Carayannis, E. G. (2017a) "The effect of social networking sites and absorptive capacity on SMES'innovation performance", The Journal of Technology Transfer, Vol. 42 No. 2, pp. 409-424.

- Scuotto, V., Del Giudice, M. and Obi Omeihe, K. (2017b) "SMEs and Mass Collaborative Knowledge Management: Towards understanding the role of social media networks", Information Systems Management, (just-accepted).

- Scuotto, V., Del Giudice, M., della Peruta, M. R. and Tarba, S. (2017c) "The performance implications of leveraging internal innovation through social media networks: An empirical verification of the smart fashion industry", Technological Forecasting and Social Change, Vol. 120, pp. 184-194.

- Sigala, M. and Chalkiti, K. (2015), "Knowledge management, social media and employee creativity", International Journal of Hospitality Management, Vol. 45, pp.44-58. 
- Social Media Today (2017), "How Much Time Do People Spend on Social Media?", Social Media Today, URL: http://www.socialmediatoday.com/marketing/how-much-time-do-peoplespend-social-media-infographic, Available. Accessed: 1st May 2017.

- Soto-Acosta, P., Casado-Lumbreras, C., Cabezas-Isla, F. (2010), "Shaping human capital in software development teams: the case of mentoring enabled by semantics", IET Software, Vol. 4 No. 6, pp. 445-452.

- Soto-Acosta, P; Colomo-Palacios, R., Popa, S. (2014), "Web knowledge sharing and its effect on innovation: an empirical investigation in SMEs", Knowledge Management Research \& Practice, Vol. 12 No.1, pp. 103-113.

- Tashakkori, A. and Teddlie, C. (2003), "The past and future of mixed methods research: From data triangulation to mixed model designs", Handbook of Mixed Methods in Social and Behavioural Research, pp. $671-701$.

- Tidd, J. and Bessant, J. (2009), Managing Innovation. Integrating Technological, Market and Organizational Change. 4th ed, John Wiley \& Sons, London.

- Timmons, J. A. and Spinelli, S. (2008), New Venture Creation: Entrepreneurship for the 21st Century, $8^{\text {th }}$ ed, McGraw Hill, London.

- Tranfield, D., Young, M., Partington, D., Bessant, J. and Sapsed, J. (2006), "Building knowledge management capabilities for innovation projects", World Scientific Book Chapters, pp.126-149.

- Tsimonis, G. and Dimitriadis, S. (2014), "Brand strategies in social media", Marketing Intelligence and Planning, Vol. 32 No. 3, pp. 328-344.

- Vuori, V. and Okkonen, J. (2012), "Knowledge sharing motivational factors of using an intraorganizational social media platform".

- Zhao, Y., Li, Y., Lee, S. H. and Chen, L. B. (2011) "Entrepreneurial orientation, organizational learning, and performance: Evidence from China", Entrepreneurship Theory and Practice, Vol. 35 No. 2, pp. 293-317. 


\section{Question Bank}

1. To what extent are you involved in decision making, towards creative and innovative activities?

2. To what extent do you believe that being entrepreneurial is a key driver in the work that you perform within your SME?

3. In what ways can an organisation's KM involve a wide variety of the workforce, encouraging greater stability and a pooling of resources?

4. To what extent has SMU increased the Organisation's awareness of specific stakeholders, including potential consumers?

5. KM is a core function within your businesses planning, development and resource allocation, towards marketing a new product and/or service. Discuss.

6. In what ways does an SMEs customer service improve with the use of SMU?

7. Do you feel that real-time feedback from consumers via SM platforms is more valuable than banks of codified data. If so, why?

8. Managers may believe that KM does not prepare a SME for the fluctuating marketplace and consumer preference. Discuss.

9. To what extent do you believe that the brand and vision of SMEs, in general, has been enhanced through greater SMU?

10. SMEs interaction with stakeholders via SMU increases the entrepreneurial intention of the workforce. Can you recall instances, within your SME, that can relate to this? Provide some examples.
How can SMEs shape the implementation of social media towards new ways of productivity?
1. What KM techniques or processes are used within your SME?

2. In what ways do management within your SME instil an entrepreneurial culture, where continuous research and development is expected from your role?

3. If you have concerns about the way in which your SME deals with information, and the management of knowledge from the external environment, what solutions do you feel could be implemented?

4. Provide evidence to suggest that your SME is technologically up to date with the latest contemporary KM techniques, through sufficient SMU.

5. To what extent do you believe your SME can improve its performance from revised KM processes?

6. In what ways has your SME been able to market its product or services more widely from SM platforms?

7. To what extent do you believe that there is a link between KM and financial success of your SME?

8. To what extent do you feel that SMU, and efficient KM, bridges an economic and resource gap between SMEs and multinational organisations?

9. Provide some evidence that knowledge retention is a core requirement towards the sustainability of your SME, with this being clearly stated by management.

10. Do you believe that SM engagement enables your SME to create and retain a competitive advantage in your respective market? If so, provide some examples. 
2. Thematic Realisation: Explanatory Approach

\begin{tabular}{|c|c|c|c|}
\hline Question & Sample & Recurring Factors & Critical Themes \\
\hline $\begin{array}{l}\text { What is the influence of } \\
\text { social media in } \\
\text { facilitating KM } \\
\text { innovation within SMEs? }\end{array}$ & $\begin{array}{l}\text { "The variety of social media means we can realise } \\
\text { greater market opportunities" } \\
\text { "We do, however, have to conduct continuous } \\
\text { screening and training to find the right people" } \\
\text { "There needs to be efficient management of market } \\
\text { knowledge, that is regular, consistent and } \\
\text { purposive" } \\
\text { "Social media channels allows us to bridge any } \\
\text { gaps, and build a reputable stakeholder } \\
\text { relationship" } \\
\text { "It informs us of market gaps, and encourages } \\
\text { wider consumer engagement" } \\
\text { "I have found it to be highly motivating for my staff, } \\
\text { and encourages innovative activities" } \\
\text { "My company relies on social media to seek the } \\
\text { relevant data" } \\
\text { "Social media enhances the level of our } \\
\text { organisational knowledge which informs planning } \\
\text { and operational activities" } \\
\text { "The pressure to adopt social media presents on- } \\
\text { going structural and personnel issues" } \\
\text { "The data we recover is essential towards } \\
\text { maintaining cost and resource efficiency" } \\
\text { "We can adequately build our brand, and realise a } \\
\text { distinct competitive advantage in the market" } \\
\text { "Employees are more creative and discuss } \\
\text { entrepreneurialism habitually" }\end{array}$ & 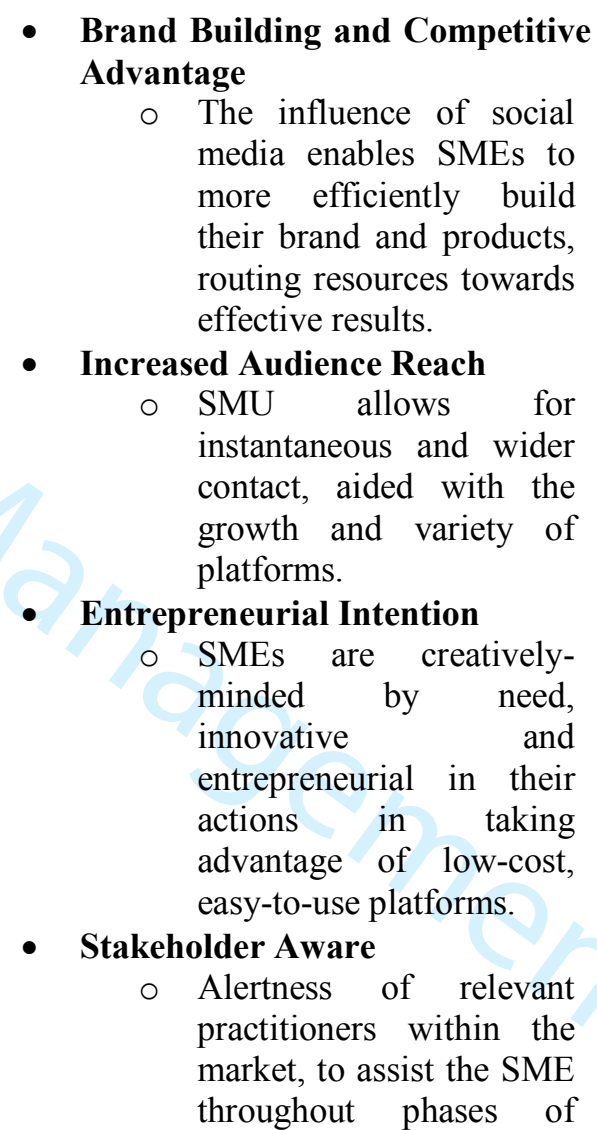 & 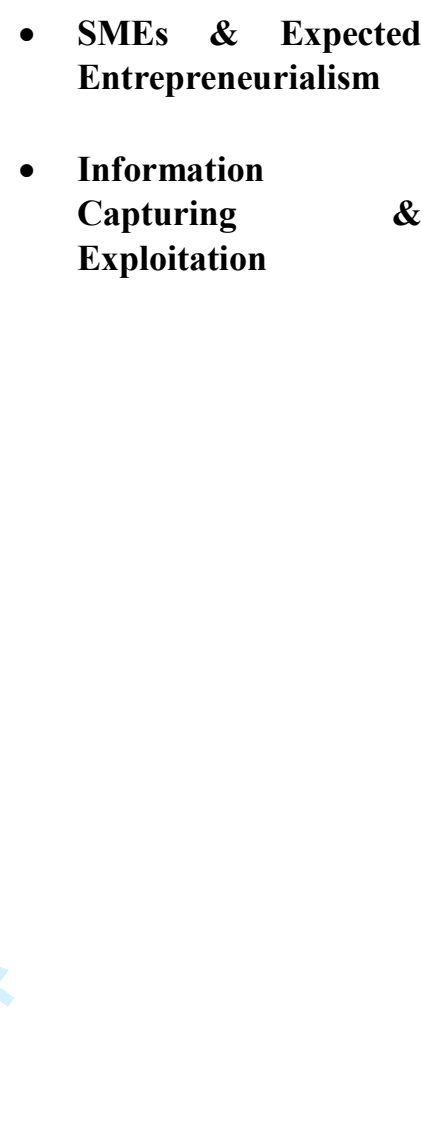 \\
\hline
\end{tabular}




\begin{tabular}{|c|c|c|c|}
\hline & $\begin{array}{l}\text { "This consistent communication through SMU is } \\
\text { instantaneous, and allows us to show that we care } \\
\text { about what we do" }\end{array}$ & $\begin{array}{l}\text { product or } \text { service } \\
\text { marketability. } \\
\text { - Knowledge Retention } \\
\text { O High, essential, costs of } \\
\text { employing requisite } \\
\text { individuals, who embed } \\
\text { durable KM processes. }\end{array}$ & \\
\hline $\begin{array}{l}\text { How can SMEs shape the } \\
\text { implementation of social } \\
\text { media towards new ways } \\
\text { of productivity? }\end{array}$ & $\begin{array}{l}\text { "We see the impact on our financial, human, social } \\
\text { and physical resources" } \\
\text { "Fresh ideas, fresh people, fresh processes, is what } \\
\text { will make our company tick in the social media } \\
\text { age", } \\
\text { "When you appreciate the benefits of social media, } \\
\text { you just have to adapt and ensure your brand is } \\
\text { displayed through all available online channels" } \\
\text { "Our organisational vision is now based on what } \\
\text { we can now do online, and what information we can } \\
\text { source about what we do, and how we can do it } \\
\text { better" } \\
\text { "The company gets to express itself better, with the } \\
\text { variety of platforms and ways in which we can } \\
\text { connect" } \\
\text { "Efficient management of our market research } \\
\text { directly informs how we contact and communicate } \\
\text { existing and new customers - it is exciting times!" } \\
\text { "Although not every platform is helpful, we try to } \\
\text { be as effective and as practical as possible. We } \\
\text { listen to our customers, as being online, they cannot } \\
\text { be avoided or ignored" } \\
\text { "Times change, so we must change - increasing the } \\
\text { profitable capabilities of our company is what we } \\
\text { must assess" }\end{array}$ & 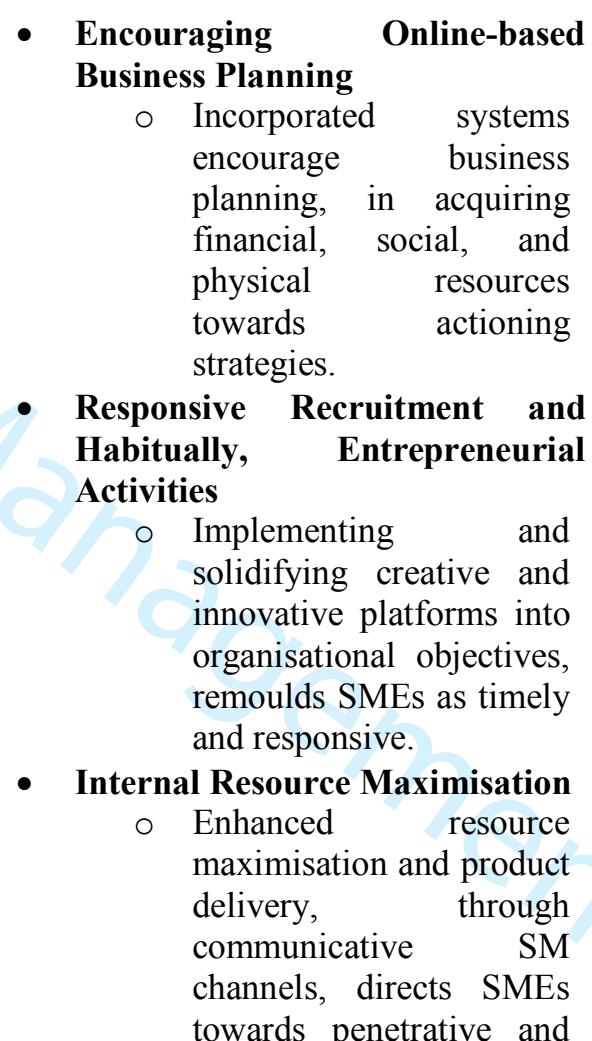 & $\begin{array}{ll}\text { - } & \text { Formalised } \\
\text { Entrenched } & \text { KM } \\
\text { Processes } & \\
\text { - } & \text { Active } \\
\text { Marketing } & \text { SMU } \\
\text { Consultancy Tools }\end{array}$ \\
\hline
\end{tabular}


"Market facing engagement is our main reason for increasing our exposure through social media"

"We experience a certain degree of freedom to really show what we are all about" new market strategies.

- Enhanced Product Assessment

○ In keeping apace with competition, industrial advancements and macroeconomic fluctuations, SMU facilitates instant change or amendments to entry strategies and representations.

- Online Alertness

- KM processes motivate the workforce towards relevant activities within the sector, based on reliable statistical and anecdotal data and information from associated stakeholder groups. 


\section{RCIDTA Model Explicated}

\begin{tabular}{|c|c|c|c|}
\hline Phases & Processes & Implications & References \\
\hline 1. Research & 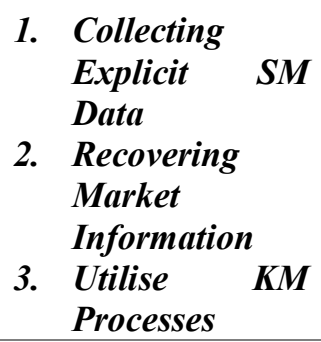 & $\begin{array}{l}\text { - Whilst social networks are designed to be accessible and user friendly some time } \\
\text { investment is required to establish what any added value will bring to the business. } \\
\text { - This is likely to initially take the form of some basic online research. } \\
\text { - Subsequently, it is likely that some primary research will be undertaken generally within } \\
\text { trusted networks to confirm the 'hunch' in relation to maximising the potential benefit of } \\
\text { SMU. }\end{array}$ & $\begin{array}{l}\text { (Ardichvili et al., } \\
\text { 2006; Lanskoronskis } \\
\text { et al., 2009; Bharati } \\
\text { et al., 2015) }\end{array}$ \\
\hline 2. Concept & 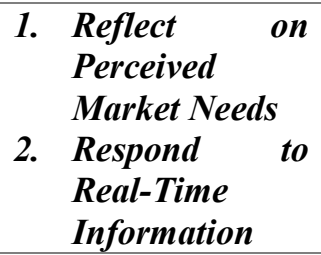 & $\begin{array}{l}\text { - Having developed the 'hunch' the conception stage is concerned with strengthening this } \\
\text { by reflecting on available data and applying this to what is known about the business, its } \\
\text { customers and what they want. } \\
\text { - KM is, in itself, a market and unsurprisingly entrepreneurs have identified the opportunity } \\
\text { that the challenge of KM raises for SMEs. }\end{array}$ & $\begin{array}{l}\text { (Chua and Banerjee, } \\
\text { 2013; Ritala et al., } \\
2013 \text {; Garrido- } \\
\text { Morena et al., 2015) }\end{array}$ \\
\hline
\end{tabular}




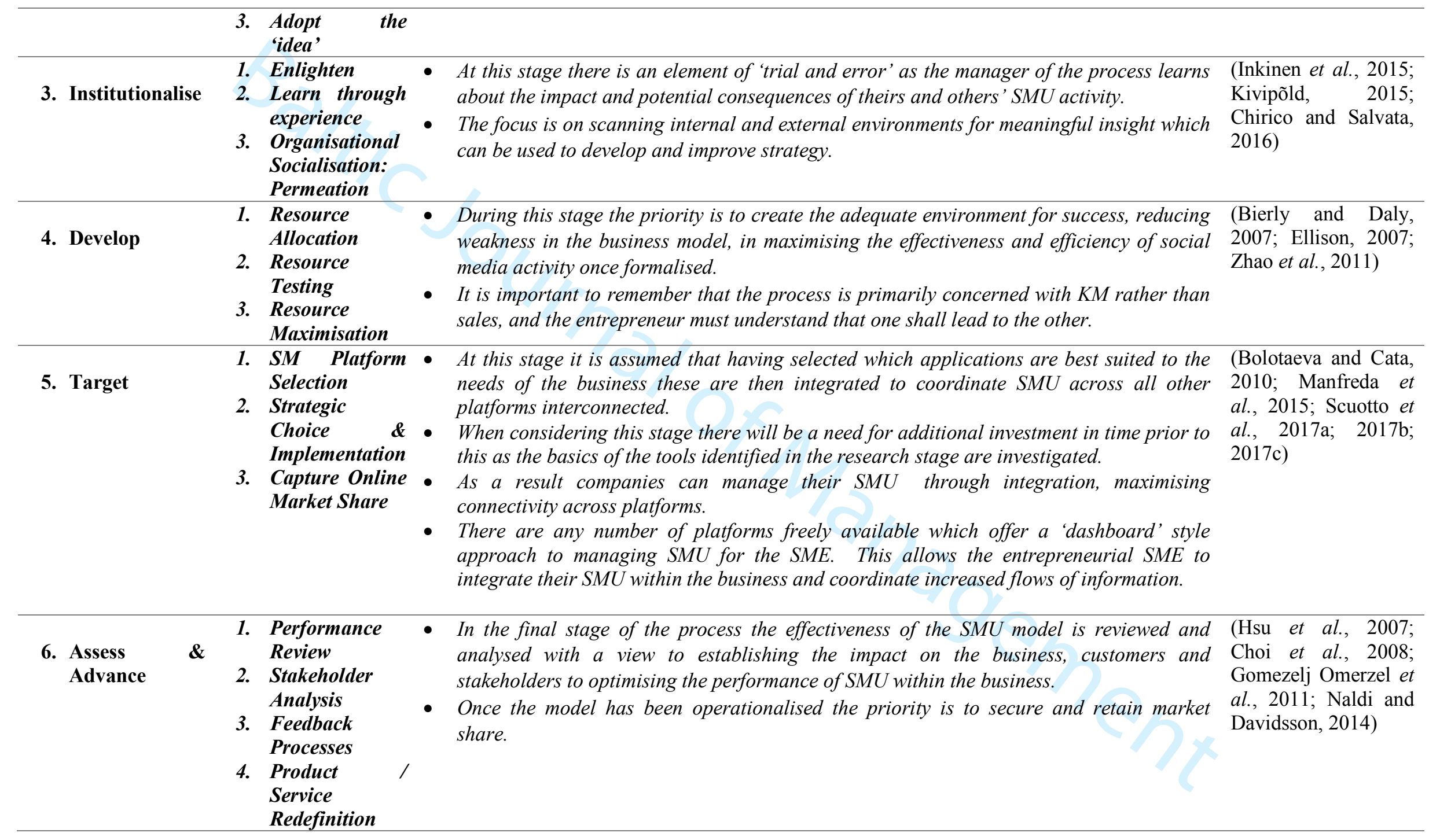


